\title{
In vivo biotransformations of indium phosphide quantum dots revealed by X-ray micro-spectroscopy
}

Giulia Veronesi, ${ }^{\dagger *}$ Maria Moros, ${ }^{\uparrow, \&}$ Hiram Castillo-Michel, ${ }^{\dagger}$ Lucia Mattera, ${ }^{\mp, \S}$ Giada Onorato", Karl David Wegner, ${ }^{\mp, \#}$ Wai Li Ling," Peter Reiss, ${ }^{\mp}$ Claudia Tortiglione I* $^{*}$

† Univ. Grenoble Alpes, CNRS, CEA, Laboratory CBM, 17 rue des Martyrs, 38000 Grenoble, France

$\dagger$ ESRF, the European Synchrotron. 71 Avenue des Martyrs, 38000 Grenoble, France

『 Istituto di Scienze Applicate e Sistemi Intelligenti “E. Caianiello”, Consiglio Nazionale delle Ricerche, Via Campi Flegrei 34, 80078 Pozzuoli, Italy

\& Aragon Materials Science Institute and Ciber-BBN. Campus Rio Ebro,C/ Mariano Esquillor s/n 27. 50018 Zaragoza, Spain.

Ғ Univ. Grenoble Alpes, CEA, CNRS, IRIG, SyMMES, Laboratoire STEP, 17 rue des Martyrs, 38000 Grenoble, France.

ו Univ. Grenoble Alpes, CEA, CNRS, IBS, F-38000 Grenoble, France

$\S$ Present address: Department of Information and Electrical Engineering and Applied Mathematics (DIEM), University of Salerno, Via Giovanni Paolo II 132, 84084 Fisciano, Italy.

\# Present address: Federal Institute for Materials Research and Testing (BAM), Division 1.2 Biophotonics, Richard-Willstätter-Straße 11, 12489 Berlin (Germany)

* Giulia Veronesi e-mail: giulia.veronesi@cea.fr; Claudia Tortiglione e-mail: claudia.tortiglione@cnr.it 


\begin{abstract}
Many attempts have been made to synthesize cadmium-free quantum dots (QDs), using nontoxic materials, while preserving their unique optical properties. Despite impressive advances, gaps in knowledge of their intracellular fate, persistence and excretion from the targeted cell or organism still exist, precluding clinical applications. In this study, we used a simple model organism (Hydra vulgaris) presenting a tissue grade of organization to determine the biodistribution of indium phosphide (InP) based QDs by X-ray fluorescence imaging. By complementing elemental imaging with In L-edge X-ray Absorption Near Edge Structure, unique information on in situ chemical speciation was obtained. Unexpectedly, spectral profiles indicated the appearance of In-O species within the first hour posttreatment, suggesting a fast degradation of the InP QD core in vivo, induced mainly by carboxylate groups. Moreover, no significant difference in the behaviour of bare core QDs and QDs capped with an inorganic $\mathrm{Zn}(\mathrm{Se}, \mathrm{S})$ gradient shell was observed. The results paralleled those achieved by treating animals with an equivalent dose of indium salts, confirming the preferred bonding type of $\mathrm{In}^{3+}$ ions in Hydra tissues. In conclusion, by focusing on the chemical identity of indium along a $48 \mathrm{~h}$ long journey of QDs in Hydra, we describe a fast degradation process, in absence of evident toxicity. These data pave the way to new paradigms to be considered in the biocompatibility assessment of QD-based biomedical applications, with greater emphasis on the dynamic of in vivo biotransformations, and suggest strategies to drive the design of future applied materials for nanotechnology-based diagnosis and therapeutic.
\end{abstract}

Keywords: quantum dots, indium phosphide, Hydra vulgaris, X-ray Absorption Spectroscopy, X-Ray Fluorescence imaging, in vivo. 


\section{Introduction}

At the forefront of nano-biotechnology research, QDs are recognized as novel, high-performance biological probes due to their unique optical properties, including a high photoluminescence quantum yield (PL QY), a broad absorption spectrum coupled with narrow emission, and remarkable photostability. ${ }^{1}$ In addition to these properties, largely depending on the core composition and size, and on surface passivation by an inorganic shell, organic coatings used for QD stabilization in aqueous media offer anchoring possibilities for other molecules, adding specificity and functional activity. ${ }^{2}$ The historical focus of the community was centred on CdSe-based QDs fuelled by the development of efficient synthesis methods, making them the state-of-the-art material for further manipulation, implementation and investigation. Given the inherent toxicity of cadmium, however, there has been a push by regulatory agencies to limit its content in manifold industrial and academic applications including photovoltaics, light emitting diodes, bioimaging, and drug delivery. Therefore, InP based QDs emerged as an attractive alternative to $\mathrm{CdSe}$ QDs because they possess similar optoelectronic properties but a lower intrinsic toxicity, ${ }^{3-5}$ which makes them suitable for applications spanning from optoelectronics to nanomedicine. ${ }^{6,7}$

However, while the roles played by chemical composition, size and shape, ${ }^{8}$ outer inorganic and organic shells ${ }^{9}$ have been intensively investigated in toxicity studies, ${ }^{10}$ other mechanisms need to be thoroughly dissected for a safe use of QDs in biomedicine. ${ }^{11}$ These include the route of uptake and the intracellular trafficking events up to secretion. In presence of complex biological fluids such as blood or serum, immediate binding of diverse biomolecules on the QD surface forms the so called protein corona. ${ }^{12}$ This new biological identity will govern the interaction between QD and cell membrane, affecting cell uptake mechanisms and bioactivity. Of utmost importance, although rarely investigated, are also the chemical reactions undergone by QDs in the corrosive intracellular milieu, which may result in their degradation and, eventually, complete dissolution. ${ }^{13}$ The release of molecular components and/or metal ions (e.g. $\mathrm{Ag}^{+}, \mathrm{Cd}^{2+}$ or $\mathrm{In}^{3+}$ ) can give rise to cytotoxic effects, preventing clinical applications. Thus, knowing how long bare or capped QDs stay intact inside cells and organs and understanding the mechanisms and kinetics of QDs degradation, including the in vivo mechanisms used by the cells to degrade and remove the exogenous material, are both fundamentally and clinically significant, affecting the possibility to use semiconductor nanocrystals for diagnosis and therapeutic. In this sense, several tools can probe QDs biodistribution, persistence and chemical state in a given cell/tissue, providing either spatial or chemical information. 
Due to the QDs brilliance and photostability, optical fluorescence microscopy is the most obvious imaging tool for direct mapping of QDs in cells and tissues (in vivo or post fixation), and for kinetic studies. ${ }^{14}$ Further conventional tools at the other end of the imaging resolution range include Transmission Electron Microscopy (TEM) or Scanning Electron Microscopy (SEM), which can detect individual QDs with nanometer resolution. Yet, these tools do not provide global information on the whole animal/tissue composition, nor on the QD chemical state. Techniques such as Inductively Coupled Plasma Spectroscopy (ICP), on the other hand, may precisely quantify elemental composition but lack spatial information. Other indirect methods based on the detection of free metal ions representing the QDs degradation products have been used, such as fluorescent dye-based assays relying on the increased fluorescence of a dye upon binding free $\mathrm{Cd}^{2+}$ ions, ${ }^{13}$ or lysosomal functional assays, ${ }^{9}$ presenting similar limits. In this scenario, synchrotron X-Ray Fluorescence (XRF) imaging is a powerful technique that enables the detection of exogenous elements together with tissue composition, with subcellular resolution, ppm sensitivity, and low background signal, in the nearly native state and without staining.

Here we made use of XRF imaging coupled to in situ X-ray Absorption Near Edge Structure (XANES) spectroscopy to highlight the biodistribution and chemical state of InP based core and core/shell QDs in the model organism Hydra vulgaris. Over the last decade this model system, classically used for developmental biology, entered the materials science field. The simple body anatomy, shaped as a hollow tube made of two cell layers, one facing the outer aqueous environment (the ectoderm) and the other the inner body cavity (the endoderm), emerged as a unique tool to test a variety of nanomaterials for their toxic effect or bioactivity. Challenged with many different inorganic nanoparticles, including Cd-based QDs, ${ }^{14-18}$ gold nanoparticles (NPs) ${ }^{19-21}$ carbon nano-onions, ${ }^{22}$ silica oxide NPs, ${ }^{23}$ and iron oxide NPs, ${ }^{24}$ this tissue-like animal has been employed for a plethora of applications spanning from nanotoxicology to NP mediated hyperthermia and drug delivery, ${ }^{25}$ with high translational impact, yet reducing vertebrate experimentation. Nevertheless, in none of these works was it possible to extract information on the chemical state of the NPs following cell uptake, which motivated the present investigation.

The in vivo behaviour of two different QDs was compared, namely bare InPZnS QDs ("core" QDs, C-QDs) and InPZnS/Zn(Se,S) core/shell QDs (CS-QDs) obtained after growth of a $\mathrm{Zn}(\mathrm{Se}, \mathrm{S})$ gradient shell on top of the C-QDs; both were afterwards coated with penicillamine to render them water-soluble. The thickness 
of the protecting shell ( $\mathrm{ZnS}$ or $\mathrm{ZnSe} / \mathrm{ZnS})$ is expected to have a dramatic impact on the stability and trafficking inside cells. An integrated multilevel analysis on the effect of these QDs on Hydra was recently performed. ${ }^{26}$ The assessment of several toxicity endpoints indicated a higher toxicity of C-QDs compared to CS-QDs, whereas both were far less toxic than penicillamine coated CdSe/ZnS QDs. Moreover, elemental analysis by ICP showed similar indium content in animals treated with either C-QDs or CS-QDs suggesting similar internalization rates, and that the higher toxicity of the former is due to different kinetics of degradation or diverse speciation in vivo. In order to obtain deeper insights into the mechanism underlying the observed effect, we studied the biodistribution and speciation of the two types of QDs in Hydra tissues at different times post treatment (p.t.), and by means of in situ XANES spectroscopy we merged spatial and chemical information. We observed unexpectedly fast dynamics of QDs degradation, occurring within the first hour p.t., bringing insight into the intracellular fate of QDs and suggesting new strategies to help the design of safer nanocrystals for future biomedical applications.

\section{Results and Discussion}

\section{InP QD synthesis and characterization}

Alloyed InPZnS C-QDs and InPZnS/Zn(Se,S) CS-QDs were synthesized in organic solvents and transferred to the aqueous phase using penicillamine (Figure S1). In earlier studies, we have shown that penicillamine combines the advantages of low non-specific binding in biological surrounding due to its zwitterionic character, compactness and lower tendency for disulphide formation than the more widely used cysteine. ${ }^{27}$ The latter parameter is of paramount importance for preserving high PL QY, as disulphides act as efficient fluorescence quenchers. C-QDs were synthesized using a single-step heat-up method. ${ }^{28,}{ }^{29}$ Pure InP or InZnP core QDs prepared without addition of a sulphur source (i.e. 1-dodecanethiol) completely lost their fluorescence during aqueous phase transfer and were therefore not considered in the present study. For the synthesis of CS-QDs a two-step method was used, in which a $\mathrm{Zn}(\mathrm{Se}, \mathrm{S})$ gradient shell was grown on top of the C-QDs. ZnSe has a lower lattice mismatch $(3.3 \%)$ than $\mathrm{ZnS}(7.7 \%)$ with $\mathrm{InP}$, and acts as a lattice adapter favouring the growth of the outermost $\mathrm{ZnS}$ shell. ${ }^{30-31}$

The presence of a passivating shell around the C-QDs has a significant influence on their photophysical properties. As shown in Figure 1A, the absorbance and PL 
spectra of CS-QDs show a red shift of $15 \mathrm{~nm}$ in comparison to C-QDs, which is a consequence of the weaker confinement induced by the gradient $\mathrm{Zn}(\mathrm{Se}, \mathrm{S})$ shell. In time-resolved PL measurements, the contribution of trap-related de-excitation processes is reduced in the case of CS-QDs, as indicated by the increase of the average PL decay time from 71 ns to 95 ns (Table S1, Figure S2A). Growth of the additional $\mathrm{Zn}(\mathrm{Se}, \mathrm{S})$ shell also leads to an increase of the PL intensity in the aqueous phase by a factor of 5. Evaluation of the hydrodynamic diameters after aqueous phase transfer by means of Dynamic Light Scattering (DLS) shows an increase from ca. $5 \mathrm{~nm}$ to $6 \mathrm{~nm}$ when comparing C-QDs and CS-QDs (Figure S2B), which is also confirmed by TEM analyses revealing a size increase from $3.7 \pm 0.4 \mathrm{~nm}$ to $4.4 \pm 0.5 \mathrm{~nm}$ (Figure S1). Small CS-QDs with a hydrodynamic diameter below $6 \mathrm{~nm}$ and zwitterionic coating are of particular interest for in vivo applications as they fulfil the requirements for renal clearance and efficient elimination from the body. ${ }^{32}$
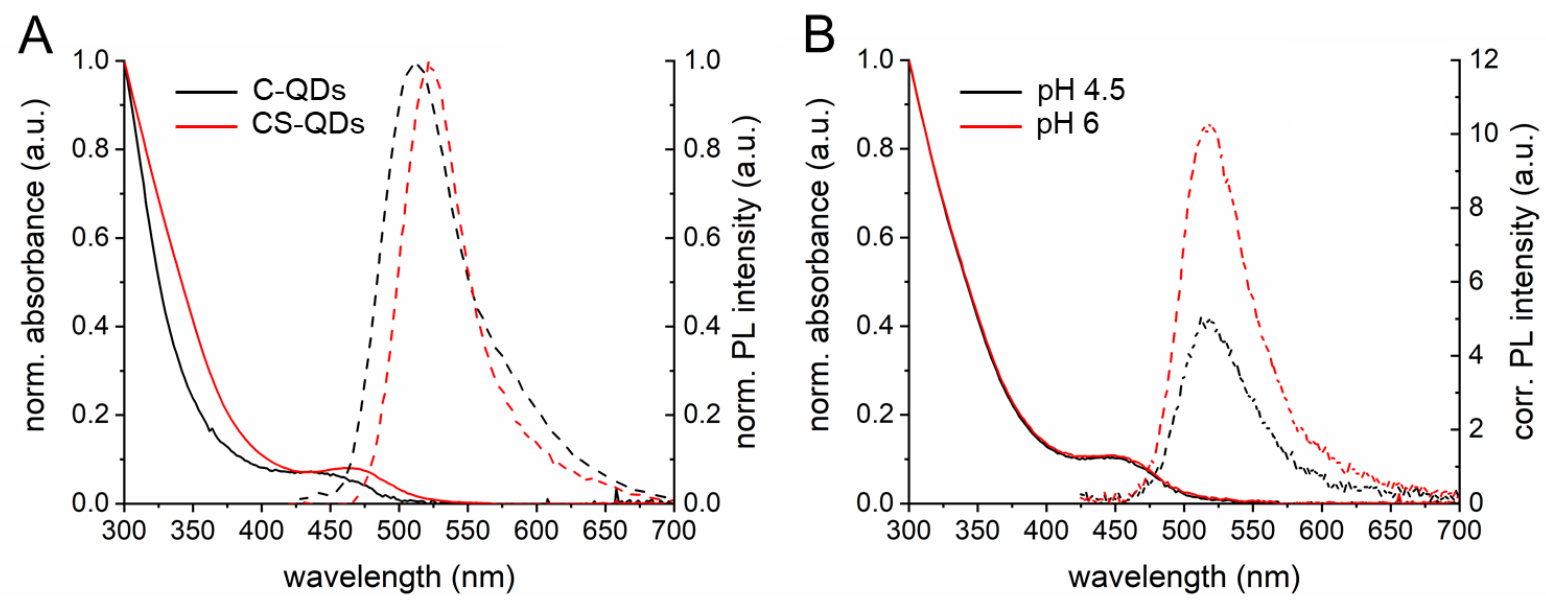

Figure 1. Photophysical characterization of QDs.

A) Normalized absorption (solid lines) and PL (dashed lines) spectra of core InPZnS QDs (C-QDs, black) and core/shell InPZnS/Zn(Se,S) QDs (CS-QDs, red). B) Normalized absorption (solid lines) and absorbance-corrected PL spectra (dashed lines) of CS-QDs at $\mathrm{pH} 6$ (black) and after one hour incubation at $\mathrm{pH} 4.5$ (red).

Next, the pH-dependent photophysical properties of the QDs were evaluated to mirror diverse subcellular environments and trafficking routes possibly recruiting QDs, and to get insight into their in vivo behavior. Acidic conditions were selected to reflect endosome/lysosome environments, likely involved in QD uptake and intracellular processing. As shown in Figure 1B, exposure of CS-QDs to the acidic 
environment leads to the irreversible decrease of their PL intensity after one hour of incubation. On the other hand, the nanocrystal core seems to stay intact because the PL peak position remains the same and the absorbance spectrum is unaltered. Longer incubation led to the complete quenching of the PL (data not shown) and finally after $24 \mathrm{~h}$ to visible aggregation and partial precipitation. The C-QDs completely lost its PL after one hour of incubation at a $\mathrm{pH}$ of 4.5 (data not shown), showcasing the importance of a shell for increasing the structural and photostability. This in vitro behaviour may partially account for the absence or very low level of fluorescence detected in animals in vivo.

\section{Exposure of Hydra vulgaris to InP QDs}

In order to visualize indium from both pristine QDs and their transformation products in Hydra vulgaris, living polyps were incubated for $3 \mathrm{~h}$ with either C-QDs or CS-QDs at $70 \mathrm{nM}$, a previously characterized dose, ${ }^{26}$ shown to have negligible effect on polyp health up to $48 \mathrm{~h}$ (Figure S3). After this time, excess QDs were removed through extensive washes and Hydra were transferred into fresh medium for up to $48 \mathrm{~h}$. This biological window was selected on the base of previous evidences collected by challenging Hydra with different nanocrystals and assessing the dynamic of internalization up to secretion. ${ }^{14,} 19$ The treatment with QDs for a limited period $(3 \mathrm{~h})$ rather than continuous was chosen in order to track the fate of internalized QDs over time, assessing the dynamics of their trafficking inside Hydra cells, from initial membrane interaction onwards. In vivo fluorescence imaging by means of optical microscopy failed to reveal any fluorescent tissue in whole animals treated with $70 \mathrm{nM} \mathrm{C-QDs} \mathrm{(Figure} \mathrm{S4),} \mathrm{at} \mathrm{any} \mathrm{period} \mathrm{of} \mathrm{incubation,}$ except rare spots detected at higher doses (100 and $200 \mathrm{nM})$. A faint signal was detected on membranes of ectodermal cells by in vivo imaging after $3 \mathrm{~h}$ of incubation with CS-QDs (Figure S4), although not detectable in cryo-sections (Figure S5). This stands out against the results obtained with CdSe based QDs where the fluorescence signal could clearly be detected both in vivo and in fixed tissue sections, as also previously observed (Figure S5). We attribute this behavior to the lower PL QY in the case of the InP-based QDs after aqueous phase transfer. The optical characterization of these QDs in water and Hydra medium previously performed, ${ }^{26}$ allowed us to exclude quenching phenomena or aggregation of these QDs in Hydra medium. Better preservation of the PL QY of InP-based QDs during aqueous phase transfer via ligand exchange can be achieved by growing an additional protective $\mathrm{ZnS}$ shell on top of the gradient shell. ${ }^{33}$ 
Animals were also treated with soluble indium species to get clues on the kinetics of uptake and accumulation of free In ions, in order to interpret the observed QD fate and speciation in vivo. Polyps were treated with $25 \mu \mathrm{M}$ In-acetate (the indium equivalent to $70 \mathrm{nM}$ QDs, as estimated by ICP-Atomic Emission Spectroscopy) for $3 \mathrm{~h}$ and then processed as for QDs. Toxicity effects assessed after $24 \mathrm{~h}$ of continuous incubation confirmed the biosafety of the indium dose, supplied both as QDs or salt (Figure S6).

\section{Fate of InP-based QDs in Hydra vulgaris}

$20 \mu \mathrm{m}$-thick sections of Hydra vulgaris obtained by cryo-sectioning of fixed specimen and histological staining show the simple structural anatomy of the polyp organized as a cell bilayer around an empty gastric cavity (Figure 2A-C). For XRF imaging tissue sections were obtained in the native frozen hydrated state. XRF images of untreated Hydra show that the most concentrated elements in the accessible energy range are $\mathrm{P}$ and $\mathrm{S}$, followed by $\mathrm{Cl}$ and $\mathrm{K}$ (Figure 2D-G). The average mass fractions of $\mathrm{P}$ and $\mathrm{S}$ in the ectoderm were calculated as $0.30 \%$ and $0.17 \%$, respectively. The distribution of these two elements, when overlaid over the same map area, provides the best contrast in the native tissue, enabling the distinction of ectoderm and endoderm layers, separated by the extracellular matrix, the mesoglea, in optimal tissue preservation conditions (Figure 2I). The high sulphur content detected may reflect the presence of numerous protein disulphide bonds within the structural components (wall, shaft, tubule) of the nematocysts, a capsule-like structure produced by nematocytes, the stinging cells responsible for the pray capture, characterizing the Cnidaria phylum. In the 90's the elements present into the nematocysts of Hydra and other cnidarian species were characterized by X-ray microanalysis, showing high values of sulphur recorded in the matrix and particularly the wall of all the cysts. ${ }^{34,}{ }^{35}$ Later on, the protein structure of the nematocyst was finely dissected, and Cys-rich proteins such as mini-collagens, ${ }^{36,37}$ nematogalactin were found, ${ }^{38}$ which may account for the high sulphur content in XRF images. Similarly, the well-defined sulphur layer between the ectoderm and the endoderm may reflect the presence of type I, type IV collagens and laminin proteins structuring the mesoglea. ${ }^{39,40}$ 

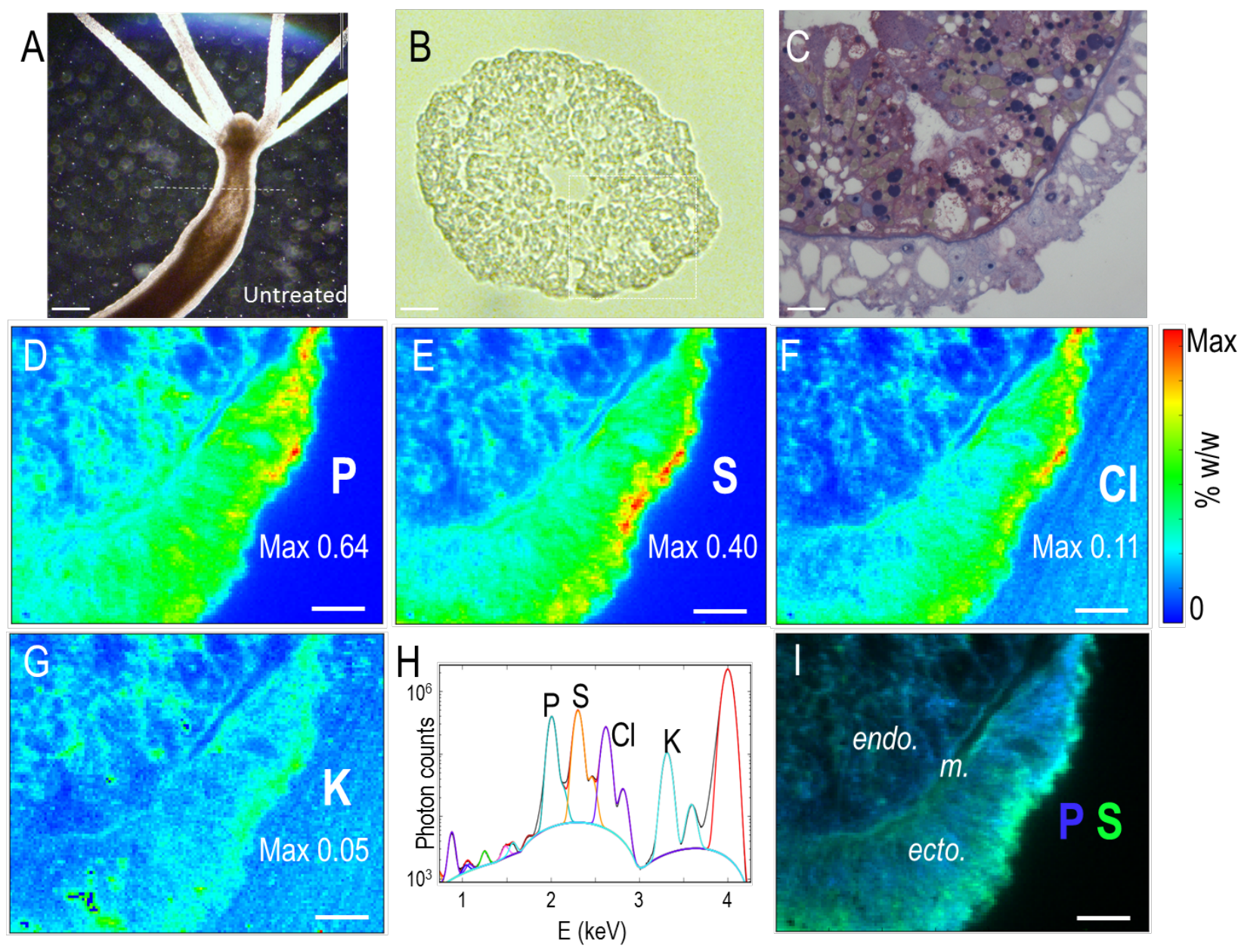

Figure 2. Morphological and elemental characterization of Hydra vulgaris.

A) A polyp imaged in dark field shows the animal simple anatomy as whole, and B) after cryosectioning (in fixed state) and C) histochemical staining. Hydra sections were stained with Periodic acid-Schiff (PAS), a routinely used method for tissue analysis, based on polysaccharide detection. The ectoderm appears as a vacuolated cell layer, while the endoderm is rich of granules, for digestive and storage functions. The two cell layers appear well separated by the mesoglea. DG) False-color quantitative images of elemental distributions (P, S, Cl, K) in a transversal section of untreated Hydra vulgaris, extracted from XRF hyperspectral images. The maximum mass fraction $(\% \mathrm{w} / \mathrm{w})$ of the corresponding element over the map area is reported on each map. $\mathrm{H})$ Sum XRF spectrum in the region corresponding to the sample area of the hyperspectral image from which images D-G were extracted. Theoretical contributions calculated for the different elements are reported as colored lines over the experimental spectrum (black). The best-fitting curve given by their sum is reported in red. I) Overlay of P (blue) and S (green) distributions in the same map area, highlighting the contrast given by native elements in unstained Hydra sections. No In contribution is detected in the control sample (In $\mathrm{L}_{\beta 1}$, also called L2M4 emission line, expected at $3.487 \mathrm{keV}$ ). ecto. $=$ ectoderm, endo. $=$ endoderm, $m .=$ mesoglea. Scale bars: $500 \mu \mathrm{m}$ in $\mathrm{A}, 200 \mu \mathrm{m}$ in $\mathrm{B}, 20 \mu \mathrm{m}$ in $\mathrm{C}-\mathrm{G}$ and $\mathrm{I}$. 
When Hydra is observed 1 h p.t. with CS-QDs, XRF hyperspectral images reveal the presence of In and the distribution of the metal within the tissue (Figure 3A-B). The observation of the XRF sum spectrum relative to putative In-rich spots in the endoderm (Figure 3A) confirms the appearance of a spectral contribution due to indium (grey curve) that partially overlaps with potassium fluorescence emission. Indium is found exclusively in the ectoderm (Figure 3C), with local concentrations up to $200 \mathrm{ppm}(0.02 \% \mathrm{w} / \mathrm{w})$ in highly localized spots and a diffuse lower signal distributed over large areas (Figure 3C). This spatial distribution has been previously observed for silver nanoparticles in different cellular models. ${ }^{41-42}$ It was explained considering that the exogenous material is internalized into the cells by endocytosis, i.e. surrounded by a cell membrane, then transported into vesicles inside the cells, transformed into the acidic environment of such vesicles, and eventually released as different metal species in the cell cytoplasm. We also obtained XRF images of the In distribution in tissue sections prepared from Hydra treated with C-QDs, at $1 \mathrm{~h}$ and $3 \mathrm{~h}$ time points (Figures S7A-B, S8A-B). Similar distributions of In species in ectodermal cells were observed, suggesting similar internalization routes for the two types of QDs. However, speciation analysis of the C-QDs colloidal suspension prior to animal exposure revealed a high percentage of In-O bonds, as in In-carboxylate $\left(\operatorname{In}\left(\mathrm{COO}^{-}\right)_{3}\right)$ and In-oxide (see next section, Figure S7D, Table S2), suggesting a degradation of the C-QDs following the phase transfer. Therefore, we focussed the in vivo speciation analysis on CS-QD, which present also superior photophysical properties and higher biosafety (Figure S3). ${ }^{26}$

The temporal evolution of the indium spatial distribution was investigated by snapfreezing the animals $3 \mathrm{~h}, 24 \mathrm{~h}$ or $48 \mathrm{~h}$ p.t. ( $3 \mathrm{~h}$ pulse) with CS-QDs. XRF images of Hydra sections reveal the presence of indium in the ectoderm at all time points (Figure 3D-F and Figure S9), whereas after $24 \mathrm{~h}$ and $48 \mathrm{~h}$ indium is detected also deep inside the inner endoderm (Figure 3E-F). The endodermal location of the metal confirms previous data showing CdSe/CdS QDs located into the endoderm after $24 \mathrm{~h}$ of incubation. ${ }^{14}$ However, it is not known whether the observed migration was due to free QDs, and if any degradation and concomitant $\mathrm{Cd}$ ion release occurred. In the present case, indium revealed through XRF imaging may be present in the form of diverse chemical species, which can be unraveled only by in situ spectroscopic investigations, as reported below. This approach is not suitable to track the transformation of $\mathrm{P}$ in the organism as phosphorus from the QDs would be undistinguishable from native phosphorus, present in all biological systems. Moreover, the concentration of native $\mathrm{P}$ is much higher than that of exogenous $\mathrm{P}$, and would mask the signal of the latter. To preclude the formation of poisonous 
phosphine gas during the degradation of the QDs, we carried out additional tests (cf. Fig. S10).
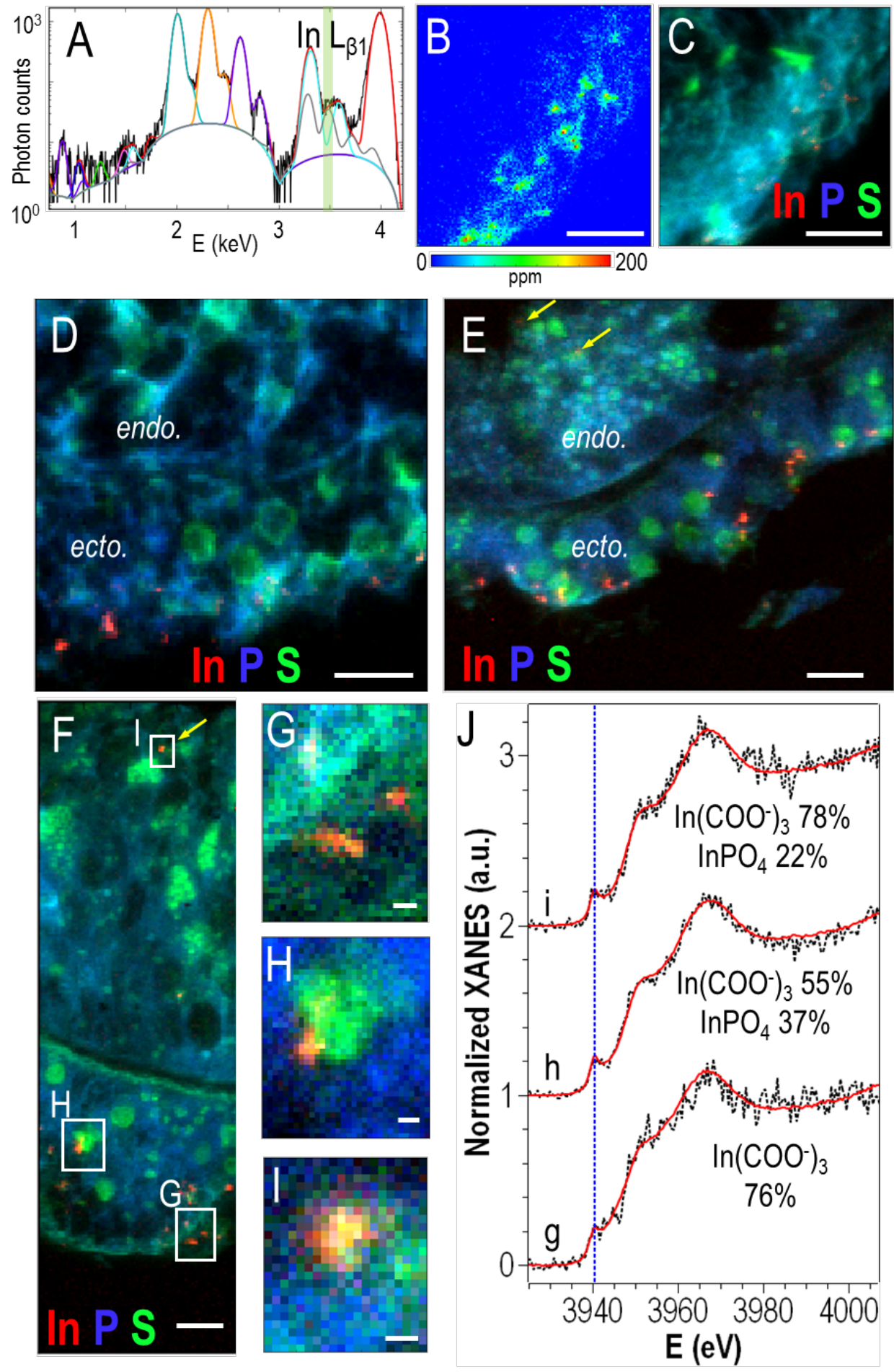
Figure 3. Time evolution of indium in Hydra vulgaris exposed to CS-QDs.

A) Sum XRF spectrum relative to In-rich areas and B) false-color quantitative image of indium distribution in a transversal section of Hydra vulgaris $1 \mathrm{~h}$ p.t. with CS-QDs. C-F) RGB representation of indium (red), sulphur (green), and phosphorus (blue) distribution in transversal sections of Hydra exposed to CS-QDs and observed after C) 1 h D) 3 h E) 24 h or F) 48 h. Pixel size $1 \times 1 \mu \mathrm{m}^{2}$. Scale bars $=20 \mu \mathrm{m}$. All maps reveal the presence of In in the ectoderm while only at $24 \mathrm{~h}$ or $48 \mathrm{~h}$ p.t. In is detected in the endoderm (yellow arrows). G-I) RGB representation of indium (red), sulphur (green), and phosphorus (blue) distribution extracted from high-resolution $\left(500 \times 500 \mathrm{~nm}^{2}\right)$ XRF imaging in selected areas of map F: outer ectoderm $(\mathrm{G})$, inner ectoderm $(\mathrm{H})$, and endoderm (I). Scale bars $=2 \mu \mathrm{m}$. J) In $\mathrm{L}_{\mathrm{II}}$-edge $\mu$ XANES spectra acquired in Hydra, on In-rich spots of maps G-I. Best-fitting curves given by linear combination of reference compounds are reported (red traces) over the corresponding experimental spectra (black dotted lines). The fraction of In-O species given by curve fitting is reported below the curves.

In order to disclose the nature of In-species detected in both the endoderm and ectoderm, and get new insights into in vivo transformations of InP-based QDs, we performed In $\mathrm{L}_{\mathrm{II}}$-edge micro-beam XANES ( $\mu$ XANES) spectroscopy on selected areas of the XRF images. The choice of the uncommon $\mathrm{L}_{\mathrm{II}}$ edge was driven by the need to disentangle the emission signal of In from that of $\mathrm{K}$, physiologically present in Hydra as well as in most biological systems. In $\mathrm{L}_{\beta 1}$ is the highest yield indium XRF emission line that does not overlap with potassium $\mathrm{K}_{\alpha}$ or $\mathrm{K}_{\beta}$ lines (Figure 3A). Therefore, the corresponding energy region was chosen to collect fluorescence detected XANES spectra, ruling out the detection of the potassium background signal. Consequently, being $\mathrm{L}_{\beta 1} \mathrm{XRF}$ emission generated by electron transitions from the M4 energy level to a core-hole in the L2 energy level, only the photoexcitation of $\mathrm{L} 2$ electrons could be detected, i.e. the In $\mathrm{L}_{\mathrm{II}}$-edge.

As a first instance, In $\mathrm{L}_{\mathrm{II}}$ XANES spectra of reference compounds were acquired (Figure 4A). The spectral features show a marked variability between different In compounds, in particular in the pre-edge region around $3940.5 \mathrm{eV}$ (blue dotted line in Figure 4A). Remarkably, a sharp pre-peak can be associated to In-O bonds, such as in In-myristate $\left(\operatorname{In}(\mathrm{My})_{3}\right)$, In-acetate $\left(\operatorname{In}(\mathrm{Ac})_{3}\right)$ and $\operatorname{In}$-phosphate $\left(\mathrm{InPO}_{4}\right)$, while the InP zinc-blende crystal structure gives rise to a pronounced shoulder in the same energy region. It is worth mentioning that $\operatorname{In}(\mathrm{My})_{3}$ and $\operatorname{In}(\mathrm{Ac})_{3}$ yield identical spectra, due to the fact that the local structure of the indium atom is the same in the two compounds: in both cases $\mathrm{In}^{3+}$ is bonded to three carboxylate ( $\mathrm{R}-\mathrm{COO}^{-}$) groups of myristate or acetate molecules. Therefore, this spectrum can be considered as representative of In-carboxylate complexes $\left(\operatorname{In}\left(\mathrm{R}-\mathrm{COO}^{-}\right)_{3}\right)$ as the ones likely to 
form in vivo, e.g. following indium binding to aspartate or glutamate side chains in proteins.
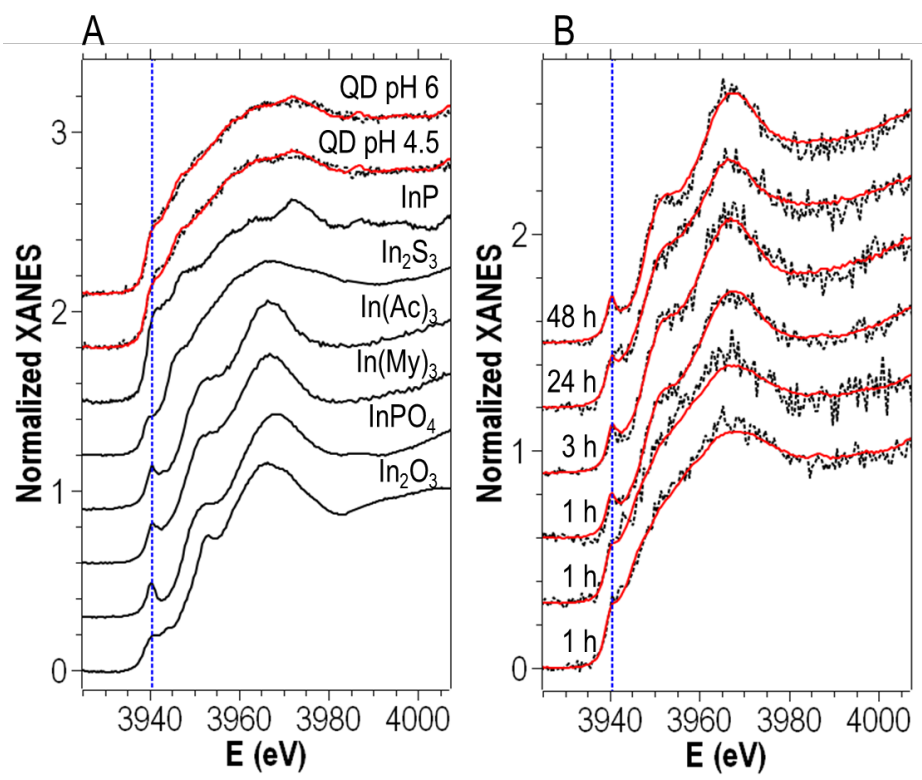

Figure 4. In vitro and in vivo X-ray Absorption Near Edge Structure spectra. Indium $\mathrm{L}_{\mathrm{II}}$-edge XANES spectra of A) indium reference compounds (solid black lines) and CS-QDs in vitro at neutral and acidic $\mathrm{pH}$ (dotted black lines). B) Selected In-rich areas detected in the ectoderm of Hydra exposed to CS-QDs and analyzed by XRF at 1 h, 3 h, 24 h or 48 h p.t. (dotted black). The best fitting curves based on linear combination fitting are reported as red solid curves over the corresponding experimental spectrum in both panels.

The XANES spectra of pristine CS-QDs in vitro, in DI water at pH 6 or after $24 \mathrm{~h}$ at $\mathrm{pH} 4.5$ were also measured. The spectra are shown in Figure $4 \mathrm{~A}$ (dotted black curves), together with their best-fitting curves given by linear combinations of reference compounds (red solid curves): the experimental spectra are reproduced by a combination of $55 \% \mathrm{InP}$ and $45 \% \mathrm{In}_{2} \mathrm{~S}_{3}$ species, regardless of the $\mathrm{pH}$ (Table 1). This proves the high stability of CS-QDs against $\mathrm{pH}$ changes. The InP and $\operatorname{In}_{2} \mathrm{~S}_{3}$ components found in QDs account for In-P and In-S bonds, respectively, in the InPZnS alloyed core. ${ }^{29}$ The same analytical protocol applied to C-QDs revealed the presence of indium oxides and carboxylates in the aqueous solution, which was interpreted as a partial degradation occurring during phase transfer in the absence of a protective shell over the InPZnS core. The analysis of Hydra exposed to CQDs is reported in Figure S7-S8, and Table S2. This shows that XANES spectroscopy of colloidal nanocrystals is a powerful characterisation tool to dissect 
their internal composition and to detect degradation during synthesis, phase transfer, or in a chosen synthetic environment.

Table 1. In vitro and in vivo speciation of indium from QDs. Results of curve fitting of $\operatorname{In}_{\mathrm{II}^{-}}$ edge XANES spectra acquired in Hydra exposed to CS-QD and in the same quantum dot in vitro. Errors relative to the last digit are reported in parenthesis. The spectra of reference compounds and best-fitting curves of QDs in vitro are reported in Figure 4A. Best-fitting curves for data acquired in Hydra are reported in Figures 3J and 4B.

\begin{tabular}{|c|c|c|c|c|c|c|}
\hline SAMPLE & $\begin{array}{c}\text { Location in } \\
\text { tissue }\end{array}$ & $\begin{array}{l}\text { InP } \\
(\%)\end{array}$ & $\begin{array}{c}\mathrm{In}_{2} \mathrm{~S}_{3} \\
(\%)\end{array}$ & $\begin{array}{c}\operatorname{In}\left(\mathrm{COO}^{-}\right)_{3} \\
(\%)\end{array}$ & $\begin{array}{c}\mathrm{InPO}_{4} \\
(\%)\end{array}$ & $\begin{array}{c}\mathrm{R}_{\mathrm{fit}} \\
\left(10^{-3}\right)\end{array}$ \\
\hline \multicolumn{7}{|l|}{ In Hydra } \\
\hline \multirow{4}{*}{ CS-QDs $1 \mathrm{~h}$} & Ectoderm & $18(4)$ & - & $82(4)$ & - & 6.3 \\
\hline & Ectoderm & $27(5)$ & $51(8)$ & $22(9)$ & - & 2.2 \\
\hline & Ectoderm & $20(7)$ & $49(10)$ & $31(10)$ & - & 4.3 \\
\hline & Ectoderm & - & $15(4)$ & $40(8)$ & $45(9)$ & 1.4 \\
\hline \multirow{4}{*}{ CS-QDs 3 h } & Ectoderm & - & - & $88(7)$ & $12(7)$ & 3.0 \\
\hline & Ectoderm & - & - & $100(9)$ & - & 5.0 \\
\hline & Ectoderm & - & - & $87(7)$ & $13(7)$ & 2.7 \\
\hline & Ectoderm & $14(8)$ & $47(12)$ & $40(15)$ & - & 5.7 \\
\hline \multirow{3}{*}{ CS-QDs 24 h } & Ectoderm & - & - & $65(6)$ & $35(6)$ & 1.9 \\
\hline & Ectoderm & - & $48(5)$ & $52(5)$ & - & 4.3 \\
\hline & Ectoderm & - & $26(4)$ & $74(4)$ & - & 2.2 \\
\hline \multirow{6}{*}{ CS-QDs 48 h } & Endoderm & - & $24(6)$ & $76(6)$ & - & 6.4 \\
\hline & Ectoderm & $8(3)$ & - & $55(9)$ & $37(9)$ & 2.0 \\
\hline & Ectoderm & - & - & $78(9)$ & $22(9)$ & 4.7 \\
\hline & Endoderm & - & $25(6)$ & $75(6)$ & - & 4.9 \\
\hline & Endoderm & - & $28(5)$ & $72(5)$ & - & 3.7 \\
\hline & Ectoderm & - & - & $46(6)$ & $54(6)$ & 2.0 \\
\hline $\operatorname{In}(\mathrm{Ac})_{3} 1 \mathrm{~h}$ & Ectoderm & - & - & $64(9)$ & $36(9)$ & 5.0 \\
\hline $\operatorname{In}(\mathrm{Ac})_{3} 24 \mathrm{~h}$ & Ectoderm & - & - & $22(10)$ & $78(10)$ & 5.6 \\
\hline \multirow{2}{*}{$\operatorname{In}(A c)_{3} 48 h$} & Ectoderm & - & - & $100(4)$ & - & 3.0 \\
\hline & Ectoderm & - & - & $48(11)$ & $52(11)$ & 7.1 \\
\hline \multicolumn{7}{|l|}{ In Vitro } \\
\hline CS-QDs pH 6 & & $55(2)$ & $45(2)$ & - & - & 0.7 \\
\hline $\begin{array}{l}\text { CS-QDs pH } \\
4.5\end{array}$ & & $54(2)$ & $46(2)$ & - & - & 0.7 \\
\hline
\end{tabular}


Selected experimental XANES spectra relative to different time points, acquired on In-rich spots of the ectodermal region of Hydra after exposure to CS-QDs, are reported in Figure 4B. The Linear Combination fitting (LCF) results for all XANES spectra acquired in vivo are reported in Table 1. We could acquire four XANES spectra $1 \mathrm{~h}$ p.t. (on In-rich spots of Figure 3C and Figure S9A), three of which are reported in Figure 4B (bottom curves). The variability in the spectra relative to the different points reflects a variability in the local indium speciation. The feature at $3940.5 \mathrm{eV}$ evolves from a shoulder, evocative of InP species, to a resolved peak, characteristic of In-O bonds. LCF results (Table 1) confirm these observations, providing a fraction of InP species between $0 \%$ and $27 \%$, varying from one point to another, for the $1 \mathrm{~h}$ sample. Considering that the fraction of InP species was $55 \%$ in pristine CS-QDs, we observed the half to complete degradation of the core already after $1 \mathrm{~h}$ in vivo. The fraction of $\operatorname{In}_{2} \mathrm{~S}_{3}$-like species instead, although very variable, ranges from a value close to the one of pristine QDs down to zero. This suggests a differential degradation of In-P and In-S bonds in the alloyed core. $1 \mathrm{~h}$ post exposure, together with the decrease of species attributable to the core, we observe the appearance of In-O-containing species: $\operatorname{In}\left(\mathrm{COO}^{-}\right)_{3}$ systematically, $\mathrm{InPO}_{4}$ in one out of four probed spots. This is an evidence of the fast degradation of the indium core in vivo, operated mainly by carboxylate groups in the biological medium that show high affinity for $\mathrm{In}^{3+}$.

$\mu$ XANES spectra acquired at longer times post exposure (Figure 4B) show a pronounced pre-peak indicative of In-O bonds, and little variability between different exposure times. LCF results (Table 1) confirm that the major indium species in the probed areas are In-carboxylate (systematically present, between $40 \%$ and $100 \%$ of all In species), followed by In-phosphates and sulphides. The InP component is estimated as $0 \%$ in almost all probed areas. Only in a single spot in the $3 \mathrm{~h}$ and one in the $48 \mathrm{~h}$ sample, the InP fraction is estimated as $14 \pm 3 \%$ and $8 \pm 3 \%$ of all In species, respectively, close to the detection limit of the technique. However, fitting the data of these two spots without InP component leads to a worse accordance, therefore we believe that InP species are actually present in very rare spots $3 \mathrm{~h}$ or longer after exposure. From this analysis alone we cannot state if these are residuals of pristine QDs or nanocrystals synthesized ex novo from in vivo bioreduction, as observed for other biological systems and nanocrystals. ${ }^{43}$ In order to investigate the capability of Hydra vulgaris to perform bioreduction of $\mathrm{In}^{3+}$, we incubated living animals with indium salts, using the QD equivalent dose, and followed the in vivo fate of this ion by means of XRF imaging and in situ XANES spectroscopy. 


\section{Fate of $\mathrm{In}^{3+}$ ions in Hydra vulgaris}

Sections of Hydra vulgaris exposed $3 \mathrm{~h}$ to indium acetate $(25 \mu \mathrm{M}$, corresponding to $70 \mathrm{nM}$ QDs) were analyzed $1 \mathrm{~h}, 24 \mathrm{~h}$ and $48 \mathrm{~h}$ p.t., with the aim to highlight the biotransformations of free $\mathrm{In}^{3+}$ ions. For the $1 \mathrm{~h}$ p.t. sample, five different areas of animal sections (about $100 \times 200 \mu \mathrm{m}^{2}$ ) from two different animals were explored, and indium was detected in only one of them (Figure 5A). Indium was found in the ectoderm of the animal, with a peculiar uniform distribution over a large area. XRF spectra confirm the presence of an emission peak attributed to indium, and allowed to estimate the average concentration of the metal to $80 \mathrm{ppm}$ in this area. At longer times p.t., indium was detected in the tissue with a more scattered distribution and higher local concentration (Figure 5B-C). XANES spectra were acquired on In-rich regions, in a single spot when possible. When the concentration was not high enough to provide good signal-to-noise ratio on a single spot, the contributions relative to several spots in the region of interest were summed up (e.g. area indicated by the yellow arrow in Figure 5A).
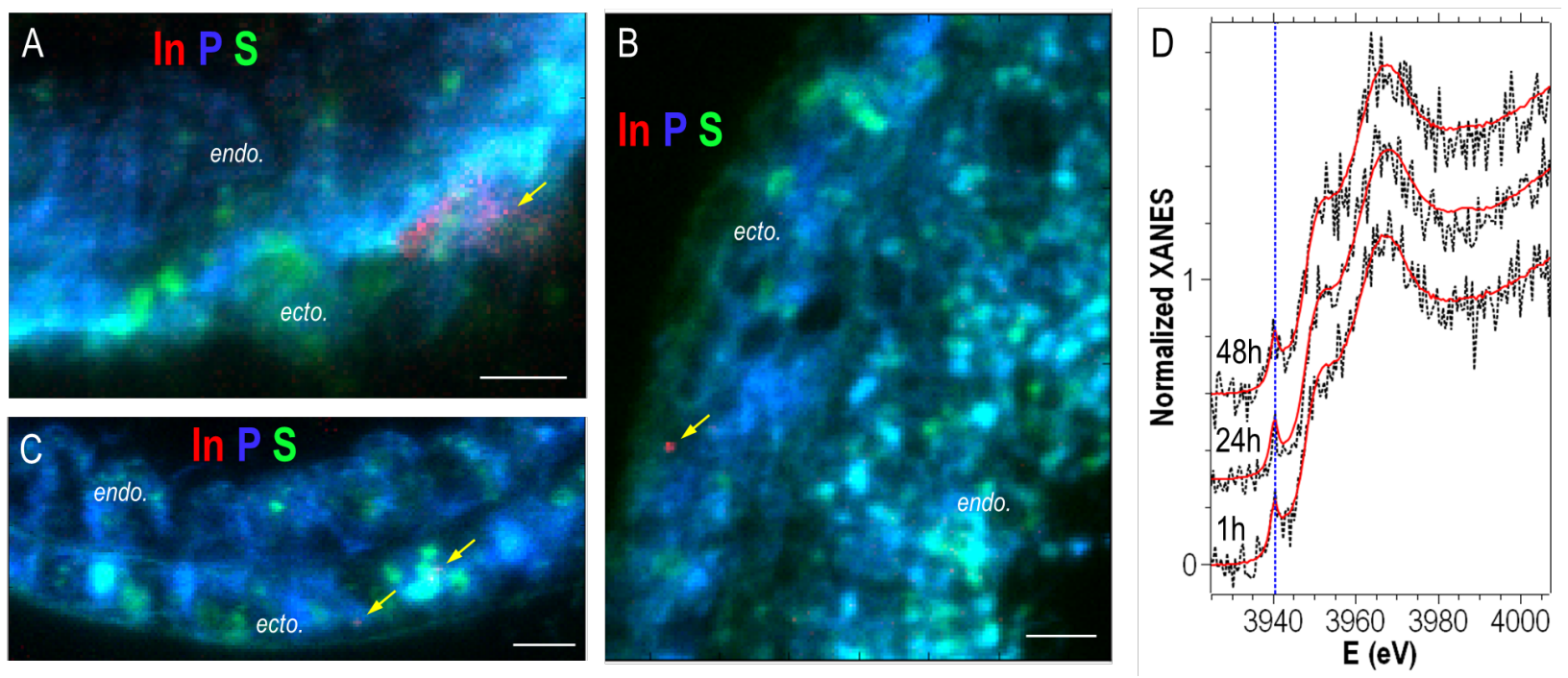

Figure 5. Elemental imaging and indium speciation in Hydra treated with indium salts. A-C) RGB representation of indium (red), sulphur (green), and phosphorus (blue) distribution in transversal sections of Hydra vulgaris exposed to indium acetate $(25 \mu \mathrm{M}$, corresponding to 70 $\mathrm{nM}$ QDs). After extensive washing, animals were observed at different time points posttreatment: A) $1 \mathrm{~h}, \mathrm{~B}) 24 \mathrm{~h}$, and C) $48 \mathrm{~h}$. Pixel size $=1 \mathrm{x} 1 \mu \mathrm{m} 2$. Scale bars $=20 \mu \mathrm{m}$. D) In $\mathrm{L}_{\mathrm{II}}$-edge $\mu X A N E S$ spectra acquired in the areas indicated by yellow arrows in maps A-C. The best-fitting curves given by linear combination of reference compounds are reported (red solid lines) over the corresponding experimental spectra (black dotted lines). 
One experimental XANES spectrum relative to each of the three time points p.t. is reported in Figure 5D (dotted curves), together with the best-fitting curves given by LCF (red solid curves). Quantitative LCF results are reported in Table 1. Experimental spectra exhibit the resolved pre-peak at $3940.5 \mathrm{eV}$ and the shoulder at $\sim 3952 \mathrm{eV}$ typical of In-O bonds. Indeed, LCF confirms the presence of only two species, $\operatorname{In}\left(\mathrm{COO}^{-}\right)_{3}$ and $\mathrm{InPO}_{4}$, from $1 \mathrm{~h}$ after exposure onward. This highlights that bioavailable $\mathrm{In}^{3+}$ is readily subjected to transformations in Hydra that lead to the formation of In-carboxylates and In-phosphates. Moreover, no InP or $\operatorname{In}_{2} \mathrm{~S}_{3}$ species are encountered in Hydra after exposure to the indium salt, which allows us to exclude the hypothesis that InP-based nanocrystals can form upon in vivo bioreduction.

\section{Conclusion}

The results of the present work integrate biodistribution data obtained by optical microscopy, with spectroscopic profiling of exogenous elements, such as indium, on a time course scale to capture the dynamic of in vivo biotransformation of fluorescent nanocrystals for biomedical applications. The synergistic information achieved by synchrotron techniques allowed tracking the fate of two types of InPbased QDs in Hydra, one of the simplest organisms that arose in animal evolution. Overcoming the problems posed by complex biological fluids, immunogenicity, tissue/organ retention, encountered in vertebrate models, this tissue-like animal provides an ideal ground to study interactions between new inorganic nano-entities and eukaryotic systems. Its translational value, due to the high conservation of the main molecular and physiological pathways, has been well documented. ${ }^{20,24-25,44-46}$

By making use of XRF imaging in the tender X-ray domain and of In L-edge XANES spectroscopy on animal tissue in the frozen hydrated state, we highlighted, for the first time in this organism, the distributions of native as well as exogenous elements, and coupled elemental distributions to reliable speciation analysis. We compared the chemical state of indium detected on tissue slices from QD treated polyps to those obtained with indium salts supplied at QD equivalent dose. LCF to reference compounds mirroring either pristine QDs or transformed species yielded quantitative information on the $\mathrm{In}^{3+}$ bonding found in situ on different tissue regions, at increasing time points post treatment. The data show unexpectedly high percentages of In-O bonds replacing In-P and In-S already at the shortest time considered ( 1 h p.t.), indicating a fast degradation process occurring in vivo. In 
contrast, the same QDs proved to be stable in water solution up to $24 \mathrm{~h}$ at acidic $\mathrm{pH}$, demonstrating that the degradation observed in Hydra vulgaris is a specific in vivo process.

These results represent a novel issue for the design of safer QDs systems and the use of QD-based imaging and therapeutic probes, focussing no more on the presence of a potentially hazardous exogenous element inside a given cell, but on its chemical complexation, which may reveal toxicity, tolerance, or suggest excretion pathway routes. Indium phosphide QDs represent an interesting and more environmentally friendly alternative to cadmium containing QDs. ${ }^{47}$ Their use in optoelectronics is already a reality, whereas their applications in medicine are under consideration: their proven resonance energy transfer properties make them good candidates for in vivo sensing. ${ }^{48}$ Moreover, their use as the basis of nanoplatforms that conjugate imaging, targeting, and drug delivery has been proposed. $^{6}$ In view of this, the biotransformations of InP-QDs and of bionanotechnologies using these nanocrystals as building blocks should be thoroughly investigated.

In light of our evidence, intracellular release and biotransformation of indium need to be properly evaluated for robust risk assessment. For instance, accumulation of intracellular In ions released from indium containing nanoparticles has been related to oxidative stress, proinflammatory response and DNA damages, and many pulmonary diseases. ${ }^{49}$ Deposition and clearance studies of indium following long term exposure of rats and mice to indium tin oxide (ITO) particles by inhalation have been also performed, ${ }^{50}$ showing the negative impact of released indium ions. Although buried by single or multiple inorganic shells, QDs may still release metal ions, due to the strong oxidant conditions of the cell cytoplasm or subcompartments. The biodistribution, pharmacokinetics and blood clearance have been recently reported for indium based QDs intravenously injected in rats. ${ }^{51,52}$ However, the picture drawn by these studies may not fully reflect the reality, due to the approach used: fluorescence microscopy is limited by the PL QY of the QDs and elemental analysis is unable to distinguish between native or degraded QDs, which has obvious toxicological implications.

The approach we adopted, based on elemental imaging and speciation analysis, is highly versatile. For instance, by targeting silver it could be applied to $\mathrm{Ag}_{2} \mathrm{~S}$ or $\mathrm{Ag}_{2} \mathrm{Se}$ QDs, recently proposed for in vivo imaging due to their emission in the NIR spectral region and low toxicity. ${ }^{53}$

It allows one to detect not only optically active nanocrystals, but also optically silent species resulting from in vivo chemical transformations of their metallic core, 
paving the way to new perspectives for their safer design and applications in nanobiotechnologies.

\section{Materials and Methods}

Chemicals. Indium acetate (99.99\%), myristic acid (>99\%), tris(trimethylsilyl)phosphine (95\%), 1-dodecanethiol (97\%), 1-octadecene (90\%), D-penicillamine, tetramethylammonium hydroxide (TMAOH), and tris(2carboxyethyl) phosphine hydrochloride solution 0.5 M (TCEP) were purchased from Sigma-Aldrich. Zinc stearate $(90 \%)$ was acquired from Riedel de Haen. Indium(III) oxide (99.9997\%), indium (III) sulphur (99.995\%), indium (III) phosphide (99.99\%) and indium (III) phosphate $(>98 \%)$ were purchased from VWR. Further solvents used within the synthesis were bought from Sigma-Aldrich, Fluka, Acros, and used without further purification.

Quantum dot synthesis. The preparation of the used precursor solutions indium myristate, zinc oleate, trioctylphosphine-selenium and trioctylphosphine-sulphur can be found elsewhere. ${ }^{54}$ InPZnS alloy nanocrystals were prepared by adding 0.1 mmol indium myristate, $0.1 \mathrm{mmol}$ zinc stearate, $0.1 \mathrm{mmol} 1$-dodecanethiol and 7.5 $\mathrm{ml} 1$-octadecene in a $50 \mathrm{~mL}$ three-neck flask. The reaction mixture was stirred and degassed for $1 \mathrm{~h}$ and then heated to $300{ }^{\circ} \mathrm{C}$ using a molten salt bath. At $100{ }^{\circ} \mathrm{C}$, a mixture of $0.1 \mathrm{mmol}$ tris(trimethylsilyl)phosphine diluted in $1 \mathrm{~mL} 1$-octadecene was quickly injected in the reaction mixture. The nanocrystal formation occurred over 25 min and was stopped by cooling the flask with a damped cloth.

For the epitaxial growth of a gradient shell of $\mathrm{ZnSe}$ and $\mathrm{ZnS}$ on the core InPZnS nanocrystals an already published protocol was used with some modifications. ${ }^{55}$ The reaction mixture was heated up to $220{ }^{\circ} \mathrm{C}$ at which $1 \mathrm{mmol}$ zinc-oleate was added dropwise. After 5 min incubation $0.2 \mathrm{mmol}$ trioctylphosphine-selenium and $0.8 \mathrm{mmol}$ trioctylphosphine-sulphur were quickly injected. The mixture was heated under vigorous stirring to $300{ }^{\circ} \mathrm{C}$ within $10 \mathrm{~min}$ and kept for another $10 \mathrm{~min}$ at this temperature before cooling down to room temperature.

The core as well as the core/shell nanocrystals were purified by precipitation with a mixture of $1: 1(\mathrm{v} / \mathrm{v})$ of chloroform and methanol and acetone and redispersed using chloroform. This purification cycle was repeated at least three times before the final nanocrystal solution was redispersed in hexane and stored under ambient temperature.

Phase-transfer. A solution of $0.2 \mathrm{M}$ D-penicillamine in $1 \mathrm{~mL}$ degassed MilliQ water $(18 \mathrm{M} \Omega \mathrm{cm})$ was prepared and $200 \mu \mathrm{L}$ of $0.5 \mathrm{M}$ TCEP was added. The $\mathrm{pH}$ 
was adjusted by dropwise addition of $25 \% \mathrm{TMAOH}$ to around 9 and the final solution degassed for $30 \mathrm{sec}$. To $1 \mathrm{~mL}$ of a $5 \mu \mathrm{M}$ nanocrystal solution in chloroform, $500 \mu \mathrm{L}$ of the phase transfer mixture was added and stirred vigorously for $1 \mathrm{~h}$ at room temperature. The upper aqueous phase containing phase transferred nanocrystals was separated from the lower organic phase und purified using a $\mathrm{NAP}^{\mathrm{TM}}$-10 size exclusion column (Sephadex ${ }^{\mathrm{TM}}$ G-25 DNA Grade from GE Healthcare) and MilliQ water as eluent. The purified nanocrystal solution was stored in the dark at $4{ }^{\circ} \mathrm{C}$.

Animal culture. Hydra vulgaris (strain Zurich, originally obtained by P. Tardent) were asexually cultured incultured in Hydra medium comprising $1 \mathrm{mM}$ calcium chloride and $0.1 \mathrm{mM}$ sodium hydrogen carbonate at $\mathrm{pH} 7 .^{56}$ The animals were fed on alternate days with Artemia nauplii at $18^{\circ} \mathrm{C}$ with a $12: 12 \mathrm{~h}$ light: dark regime. Adult polyps without bud were selected for the experiments.

In vivo treatment, imaging and tissue manipulation. Groups of 10 animals were collected in plastic multiwells and allowed to equilibrate at room temperature in $300 \mu \mathrm{L}$ of Hydra medium. The test was initiated by adding the QDs (either C-QD, CS-QD, or CdSe-based QDs) at the appropriate concentration to each well containing 10 polyps and allowing $3 \mathrm{~h}$ incubation, before extensive washes and in vivo imaging. For toxicity tests continuous incubation was extended up to $72 \mathrm{~h}$.

QD uptake was monitored in vivo, by using an inverted microscope (Axiovert 100, ZEISS) equipped with a digital colour camera (Olympus, DP70) and fluorescence filter sets (BP450-490/FT510/LP515). For imaging acquisition the software system Cell F (Olympus) was used.

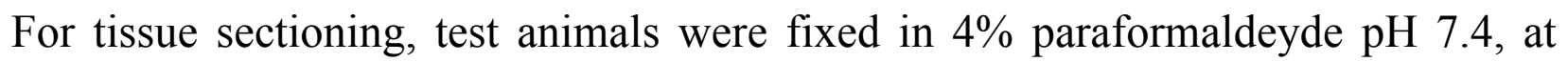
$4^{\circ} \mathrm{C}$, rinsed three times in phosphate saline buffers (PBS: $8 \mathrm{~g} / 1 \mathrm{NaCl} ; 0.2 \mathrm{~g} / 1 \mathrm{KCl}$; $1.44 \mathrm{~g} / 1 \mathrm{Na}_{2} \mathrm{HPO}_{4} \mathrm{~N}_{7} \mathrm{H}_{2} 0 ; 0.24 \mathrm{~g} / 1 \mathrm{KH}_{2} \mathrm{PO}_{4}$ ), soaked over night in $30 \%$ saccarose in PBS and then embedded in the frozen section medium OCT. Cryo-sections of 12 $\mu \mathrm{m}$ thickness were obtained by a cryostat (Leitz, digital 1760), collected on gelatine coated slides (Superfrost microscope slides, Menzel) and mounted in Aquatex mounting medium (Merck) before imaging. PAS (Periodic Acid-Schiff, Sigma Aldrich) staining was performed on hydrated tissue slices according to manufacturer instructions.

X-ray micro-spectroscopy. XRF hyperspectral images and $\mu$ XANES spectra were acquired on the beamline ID21 of the European Synchrotron Radiation Facility, ${ }^{57}$ at $110 \mathrm{~K}$ in the liquid nitrogen (LN2) cooled cryostat of the Scanning X-ray Micro- 
spectroscopy (SXM) end-station. Hydra vulgaris specimens were embedded into OCT medium and cryo-fixed by plunging in isopentane chilled with LN2. $20 \mu \mathrm{m}$ thick sections of frozen samples were obtained using Leica cryo-microtome and accommodated in a $\mathrm{Cu}$ sample holder cooled with LN2, sandwiched between Ultralene (SPEX SamplePrep) foils. The incoming X-rays were tuned to the selected energy in the $3.7-4.0 \mathrm{keV}$ range with a fixed-exit double crystal $\mathrm{Si}(111)$ monochromator $\left(\Delta \mathrm{E} / \mathrm{E} \sim 2 \cdot 10^{-4}\right)$. The beam was focused to $0.4 \times 0.9 \mu \mathrm{m}^{2}$ with a Kirkpatrick-Baez (KB) mirror system, yielding a flux of $2.8 \cdot 10^{10} \mathrm{ph} / \mathrm{s}$. The emitted fluorescence signal was detected with an energy-dispersive, large area $\left(80 \mathrm{~mm}^{2}\right)$ SDD detector equipped with Be window (XFlash SGX from RaySpec). Images were acquired at the fixed energy of $4.0 \mathrm{keV}$, by raster-scanning the sample in the X-ray focal plane, with a step of $1 \times 1 \mu \mathrm{m}^{2}$ or $0.5 \times 0.5 \mu \mathrm{m}^{2}$ and 200 to $500 \mathrm{~ms}$ dwell time. The detector response was calibrated over a thin film reference sample consisting of layers of elements in $\mathrm{ng} / \mathrm{mm}^{2}$ concentration sputtered on a $200 \mathrm{~nm}$ thick $\mathrm{Si}_{3} \mathrm{~N}_{4}$ membrane (RF8-200-S2454 from AXO), measured using the same acquisition parameters. Elemental mass fractions were calculated from fundamental parameters with the PyMca software package, applying pixel-by-pixel spectral deconvolution to hyperspectral maps normalized by the incoming current. ${ }^{58}$ Being the samples hydrated and frozen, we assumed the sample matrix to be amorphous ice $\left(11 \% \mathrm{H}, 89 \% \mathrm{O}\right.$, density $\left.0.92 \mathrm{~g} / \mathrm{cm}^{3}\right)$.

In $\mathrm{L}_{\mathrm{II}}-$ edge $\mu$ XANES spectra were acquired on selected indium-rich spots of XRF images. The energy was scanned in the $3920-4020 \mathrm{eV}$ region with $0.5 \mathrm{eV}$ steps. Ten consecutive spectra were acquired on each spot, resulting in $1 \mathrm{~s}$ integration per energy point. No radiation-induced modification was observed between consecutive spectra. Data were collected in fluorescence mode following indium decay through the $\mathrm{L}_{\beta 1}(\mathrm{~L} 2 \mathrm{M} 4$, at $3487.2 \mathrm{eV}$ ) emission line, in order to avoid interference with potassium signal. Pellets of reference compounds were measured with unfocussed beam (diameter $\sim 350 \mu \mathrm{m}$ ), in transmission mode, in the $3920-$ $4070 \mathrm{eV}$ energy range with $0.3 \mathrm{eV}$ step. In $\mathrm{L}_{\mathrm{III}}$-edge spectra of these compounds in the $3700-3850 \mathrm{eV}$ energy region were also measured, to be compared with existing literature. Model compounds were diluted with cellulose in order to provide a jump of $\sim 1$ at the absorption edge. QDs solutions were deposited on Ultralene foils, dried under $\mathrm{N}_{2}$ flow, then frozen and measured in fluorescence mode.

Spectra acquired in vivo and in vitro were analyzed by linear combination fitting (LCF), using as reference spectra: $\operatorname{InP}, \operatorname{In}_{2} \mathrm{~S}_{3}, \operatorname{In}(\mathrm{My})_{3}$ or $\operatorname{InAc}, \mathrm{InPO}_{4}, \mathrm{In}_{2} \mathrm{O}_{3}$. Data 
normalization and LCF were performed with the Athena program. ${ }^{59}$ The energy was calibrated over an $\mathrm{Ag}$ foil, by setting the energy position of its $\mathrm{L}_{\mathrm{III}}$-edge to $3351.1 \mathrm{eV}$; as a cross-check, the shoulder in the $\operatorname{In}_{2} \mathrm{O}_{3} \mathrm{~L}_{\mathrm{III}}$-edge spectrum is found at $3744.6 \mathrm{eV}$, as previously reported. ${ }^{60}$ The edge position was not allowed to vary in LCF; the only free parameters of the fits were the weights of each component. The fit was performed in the 3935-3990 eV energy range. All reference compounds were considered in a first time, then the contributions estimated to $0 \%$ were discarded. For contributions estimated below $10 \%$, the fits including or not the relative model compound were compared and the best quality (lower $\mathrm{R}$ factor) one was kept. The goodness-of-fit is indicated by the R factor, defined as: $\Sigma\left(\mathrm{x}_{\exp }-\mathrm{x}_{\mathrm{fit}}\right)^{2} /$ $\Sigma\left(\mathrm{x}_{\exp }\right)^{2}$, where $\mathrm{x}_{\exp }$ are the experimental data points, and $\mathrm{x}_{\mathrm{fit}}$ the corresponding point in the best fitting curve. Being this value well below $1 \%$ in all fits, we consider that the fits are reliable and the chosen set of reference compounds is exhaustive.

\section{Acknowledgments}

The authors acknowledge the European Synchrotron Radiation Facility for providing access to beam-time on the ID21 beamline (experiments MA-3261, MA4370). KDW and LM thank the Labex SERENADE (grant Saquado) and the French National Research Agency ANR (Grant number ANR-12-NANO-0007-03 NanoFRET) for funding. PR acknowledges financial support from Labex ARCANE (grant QDPhotocat), from CAPES/COFECUB (Grant 858/15) and from ANR (Grant number ANR-16-CE09-0015-03 Neutrinos). MM acknowledges financial support from the European Union's Horizon 2020 research and innovation programme (Marie Skłodowska-Curie grant agreement No. 660228) and Spanish Juan de la Cierva subprogram. CT acknowledges C. Viola and B. Avallone (University of Naples) and B. Miedziak (CNR-ISASI) for support in Hydra tissue histology, PAS staining and imaging. This work used the platforms of the Grenoble Instruct-ERIC Centre (ISBG; UMS 3518 CNRS-CEA-UGA-EMBL) with support from FRISBI (ANR-10-INSB-05-02) and GRAL (ANR-10-LABX-49-01) within the Grenoble Partnership for Structural Biology (PSB) for the preparation of the sample for TEM observations. The IBS electron microscope facility is supported by the Auvergne-Rhône-Alpes Region, the Fonds FEDER, the Fondation Recherche Médicale (FRM), and the GIS-IBISA.

Supporting Information Available: Additional photophysical and morphological characterization of QDs, details on the choice of the treatment dose in Hydra, 
comparison of uptake and toxicity of CdSe-based $v s$ InP-based QDs in Hydra, toxicity of In salt, distribution and speciation of C-QDs in Hydra determined by XRF imaging and in situ XANES spectroscopy, and additional XRF elemental images of sections of Hydra vulgaris exposed to CS-QDs. This material is available free of charge via the Internet at http://pubs.acs.org

\section{References}

1. Reiss, P.; Protiere, M.; Li, L. Core/Shell Semiconductor Nanocrystals. Small 2009, 5, $154-168$.

2. Wegner, K. D.; Hildebrandt, N. Quantum Dots: Bright and Versatile in Vitro and in Vivo Fluorescence Imaging Biosensors. Chem. Soc. Rev. 2015, 44, 4792-4834.

3. $\quad$ Lin, G.; Ouyang, Q.; Hu, R.; Ding, Z.; Tian, J.; Yin, F.; Xu, G.; Chen, Q.; Wang, X.; Yong, K. T. In Vivo Toxicity Assessment of Non-Cadmium Quantum Dots in BALB/c Mice. Nanomedicine 2015, 11, 341-350.

4. $\quad$ Brunetti, V.; Chibli, H.; Fiammengo, R.; Galeone, A.; Malvindi, M. A.; Vecchio, G.; Cingolani, R.; Nadeau, J. L.; Pompa, P. P. InP/ZnS as a Safer Alternative to CdSe/ZnS Core/Shell Quantum Dots: in Vitro and in Vivo Toxicity Assessment. Nanoscale 2013, 5, 307317.

5. Chibli, H.; Carlini, L.; Park, S.; Dimitrijevic, N. M.; Nadeau, J. L. Cytotoxicity of InP/ZnS Quantum Dots Related to Reactive Oxygen Species Generation. Nanoscale 2011, 3, 2552-2559.

6. Wang, Y.; Wang, Y.; Chen, G.; Li, Y.; Xu, W.; Gong, S. Quantum-Dot-Based Theranostic Micelles Conjugated with an Anti-EGFR Nanobody for Triple-Negative Breast Cancer Therapy. ACS Appl. Mater. Interfaces 2017, 9, 30297-30305.

7. Levy, M.; Bertram, J. R.; Eller, K. A.; Chatterjee, A.; Nagpal, P. Near-Infrared-LightTriggered Antimicrobial Indium Phosphide Quantum Dots. Angew. Chem. 2019. DOI: 10.1002/anie.201906501.

8. Lovric, J.; Cho, S. J.; Winnik, F. M.; Maysinger, D. Unmodified Cadmium Telluride Quantum Dots Induce Reactive Oxygen Species Formation Leading to Multiple Organelle Damage and Cell Death. Chemistry \& Biology 2005, 12, 1227-1234.

9. $\quad$ Peynshaert, K.; Soenen, S. J.; Manshian, B. B.; Doak, S. H.; Braeckmans, K.; De Smedt, S. C.; Remaut, K. Coating of Quantum Dots Strongly Defines Their Effect on Lysosomal Health and Autophagy. Acta Biomater. 2017, 48, 195-205.

10. Clift, M. J.; Brandenberger, C.; Rothen-Rutishauser, B.; Brown, D. M.; Stone, V. The Uptake and Intracellular Fate of a Series of Different Surface Coated Quantum Dots in Vitro. Toxicology 2011, 286, 58-68.

11. Reiss, P.; Carrière, M.; Lincheneau, C.; Vaure, L.; Tamang, S. Synthesis of Semiconductor Nanocrystals, Focusing on Nontoxic and Earth-Abundant Materials. Chem. Rev. 2016, 116, 10731-10819.

12. Ke, P. C.; Lin, S.; Parak, W. J.; Davis, T. P.; Caruso, F. A Decade of the Protein Corona. ACS Nano 2017, 11, 11773-11776.

13. Soenen, S. J.; Montenegro, J. M.; Abdelmonem, A. M.; Manshian, B. B.; Doak, S. H.; Parak, W. J.; De Smedt, S. C.; Braeckmans, K. The Effect of Nanoparticle Degradation on Amphiphilic Polymer-Coated Quantum Dot Toxicity: the Importance of Particle Functionality Assessment in Toxicology. Acta Biomater. 2014, 10, 732-741. 
14. Tortiglione, C.; Quarta, A.; Malvindi, M. A.; Tino, A.; Pellegrino, T. Fluorescent Nanocrystals Reveal Regulated Portals of Entry into and between the Cells of Hydra. PloS one 2009, 4, e7698.

15. Ambrosone, A.; Mattera, L.; Marchesano, V.; Quarta, A.; Susha, A. S.; Tino, A.; Rogach, A. L.; Tortiglione, C. Mechanisms Underlying Toxicity Induced by CdTe Quantum Dots Determined in an Invertebrate Model Organism. Biomaterials 2012, 33, 1991-2000.

16. Ambrosone, A.; Roopin, M.; Pelaz, B.; Abdelmonem, A. M.; Ackermann, L. M.; Mattera, L.; Allocca, M.; Tino, A.; Klapper, M.; Parak, W. J.; Levy, O.; Tortiglione, C. Dissecting Common and Divergent Molecular Pathways Elicited by CdSe/ZnS Quantum Dots in Freshwater and Marine Sentinel Invertebrates. Nanotoxicology 2017, 11, 289-303.

17. Malvindi, M. A.; Carbone, L.; Quarta, A.; Tino, A.; Manna, L.; Pellegrino, T.; Tortiglione, C. Rod-Shaped Nanocrystals Elicit Neuronal Activity in Vivo. Small 2008, 4, 17471755.

18. Quarta, A.; Ragusa, A.; Deka, S.; Tortiglione, C.; Tino, A.; Cingolani, R.; Pellegrino, T. Bioconjugation of Rod-Shaped Fluorescent Nanocrystals for Efficient Targeted Cell Labeling. Langmuir 2009, 25, 12614-12622.

19. Marchesano, V.; Hernandez, Y.; Salvenmoser, W.; Ambrosone, A.; Tino, A.; Hobmayer, B.; M de la Fuente, J.; Tortiglione, C. Imaging Inward and Outward Trafficking of Gold Nanoparticles in Whole Animals. ACS Nano 2013, 7, 2431-2442.

20. Conde, J.; Ambrosone, A.; Sanz, V.; Hernandez, Y.; Marchesano, V.; Tian, F.; Child, H.; Berry, C. C.; Ibarra, M. R.; Baptista, P. V.; Tortiglione, C.; de la Fuente, J. M. Design of Multifunctional Gold Nanoparticles for In Vitro and In Vivo Gene Silencing. ACS Nano 2012, 6, 8316-8324.

21. Ambrosone, A.; Pino, P. D.; Marchesano, V.; Parak, W. J.; de la Fuente, J. M.; Tortiglione, C. Gold Nanoprisms for Photothermal Cell Ablation in Vivo. Nanomedicine 2014, 9 , 1913-1922.

22. Marchesano, V.; Ambrosone, A.; Bartelmess, J.; Strisciante, F.; Tino, A.; Echegoyen, L.; Tortiglione, C.; Giordani, S. Impact of Carbon Nano-Onions on Hydra Vulgaris as a Model Organism for Nanoecotoxicology. Nanomaterials 2015, 5, 1331- 1350.

23. Ambrosone, A.; Scotto di Vettimo, M. R.; Malvindi, M. A.; Roopin, M.; Levy, O.; Marchesano, V.; Pompa, P. P.; Tortiglione, C.; Tino, A. Impact of Amorphous $\mathrm{SiO}_{2}$ Nanoparticles on a Living Organism: Morphological, Behavioral, and Molecular Biology Implications. Front. Bioeng. Biotechnol. 2014, 2, 37.

24. Moros, M.; Ambrosone, A.; Stepien, G.; Fabozzi, F.; Marchesano, V.; Castaldi, A.; Tino, A.; de la Fuente, J. M.; Tortiglione, C. Deciphering Intracellular Events Triggered by Mild Magnetic Hyperthermia in Vitro and in Vivo. Nanomedicine 2015, 10, 2167-2183.

25. Ambrosone, A.; Marchesano, V.; Carregal-Romero, S.; Intartaglia, D.; Parak, W. J.; Tortiglione, C. Control of Wnt/beta-Catenin Signaling Pathway in Vivo via Light Responsive Capsules. ACS Nano 2016, 10, 4828-4834.

26. Allocca, M.; Mattera, L.; Bauduin, A.; Miedziak, B.; Moros, M.; De Trizio, L.; Tino, A.; Reiss, P.; Ambrosone, A.; Tortiglione, C. An Integrated Multilevel Analysis Profiling Biosafety and Toxicity Induced by Indium- and Cadmium-Based Quantum Dots in Vivo. Environ. Sci. Technol. 2019, 53, 3938-3947.

27. Tamang, S.; Beaune, G.; Texier, I.; Reiss, P. Aqueous Phase Transfer of InP/ZnS Nanocrystals Conserving Fluorescence and High Colloidal Stability. ACS Nano 2011, 5, 93929402. 
28. Li, L.; Reiss, P. One-Pot Synthesis of Highly Luminescent InP/ZnS Nanocrystals Without Precursor Injection. J. Am. Chem. Soc. 2008, 130, 11588-11589.

29. Huang, K.; Demadrille, R.; Silly, M. G.; Sirotti, F.; Reiss, P.; Renault, O. Internal Structure of InP/ZnS Nanocrystals Unraveled by High-Resolution Soft X-Ray Photoelectron Spectroscopy. ACS Nano 2010, 4, 4799-4805.

30. Kim, K.; Lee, H.; Ahn, J.; Jeong, S. Highly Luminescing Multi-Shell Semiconductor Nanocrystals InP/ZnSe/ZnS. Appl. Phys. Lett. 2012, 101, 073107.

31. Tamang, S.; Lincheneau, C.; Hermans, Y.; Jeong, S.; Reiss, P. Chemistry of InP Nanocrystal Syntheses. Chem. Mater. 2016, 28, 2491-2506.

32. Choi, H. S.; Liu, W.; Misra, P.; Tanaka, E.; Zimmer, J. P.; Itty Ipe, B.; Bawendi, M. G.; Frangioni, J. V. Renal Clearance of Quantum Dots. Nat. Biotechnol. 2007, 25, 1165-1170.

33. Wegner, K. D.; Dussert, F.; Truffier-Boutry, D.; Benayad, A.; Beal, D.; Mattera, L.; Ling, W. L.; Carrière, M.; Reiss, P. Influence of the Core/Shell Structure of Indium Phosphide Based Quantum Dots on Their Photostability and Cytotoxicity. Frontiers in Chemistry 2019, 7, 466.

34. Tardent, P.; Zierold, K.; Klug, M.; Weber, J. X-Ray Microanalysis of Elements Present in the Matrix of Cnidarian Nematocysts. Tissue Cell 1990, 22, 629-643.

35. Gerke I.; Zierold, K.; Weber J.; Tardent P. The Spatial Distribution of Cations in Nematocytes of Hydra Vulgaris. Hydrobiologia 1991, 216, 661-669.

36. Ozbek, S.; Pertz, O.; Schwager, M.; Lustig, A.; Holstein, T.; Engel, J. Structure/Function Relationships in the Minicollagen of Hydra Nematocysts. J. Biol. Chem. 2002, 277, 4920049204.

37. Engel, U.; Ozbek, S.; Streitwolf-Engel, R.; Petri, B.; Lottspeich, F.; Holstein, T. W. Nowa, a Novel Protein with Minicollagen Cys-Rich Domains, Is Involved in Nematocyst Formation in Hydra. J. Cell Sci. 2002, 115, 3923-3934.

38. Hwang, J. S.; Takaku, Y.; Momose, T.; Adamczyk, P.; Ozbek, S.; Ikeo, K.; Khalturin, K.; Hemmrich, G.; Bosch, T. C.; Holstein, T. W.; David, C. N.; Gojobori, T. Nematogalectin, a Nematocyst Protein with GlyXY and Galectin Domains, Demonstrates Nematocyte-Specific Alternative Splicing in Hydra. Proc. Natl. Acad. Sci. U. S. A. 2010, 107, 18539-18544.

39. Shimizu, H.; Aufschnaiter, R.; Li, L.; Sarras, M. P., Jr.; Borza, D. B.; Abrahamson, D. R.; Sado, Y.; Zhang, X. The Extracellular Matrix of Hydra Is a Porous Sheet and Contains Type IV Collagen. Zoology 2008, 111, 410-418.

40. Sarras, M. P. Jr. Components, Structure, Biogenesis and Function of the Hydra Extracellular Matrix in Regeneration, Pattern Formation and Cell Differentiation. Int. J. Dev. Biol. 2012, 56, 567-576.

41. Veronesi, G.; Aude-Garcia, C.; Kieffer, I.; Gallon, T.; Delangle, P.; Herlin-Boime, N.; Rabilloud, T.; Carriere, M. Exposure-Dependent $\mathrm{Ag}^{+}$Release from Silver Nanoparticles and Its Complexation in $\mathrm{AgS}_{2}$ Sites in Primary Murine Macrophages. Nanoscale 2015, 7, 7323-7330.

42. Veronesi, G.; Deniaud, A.; Gallon, T.; Jouneau, P. H.; Villanova, J.; Delangle, P.; Carriere, M.; Kieffer, I.; Charbonnier, P.; Mintz, E.; Michaud-Soret, I. Visualization, Quantification and Coordination of $\mathrm{Ag}^{+}$Ions Released from Silver Nanoparticles in Hepatocytes. Nanoscale 2016, 8, 17012-17021.

43. Shah, M.; Fawcett, D.; Sharma, S.; Tripathy, S. K.; Poinern, G. E. J. Green Synthesis of Metallic Nanoparticles via Biological Entities. Materials 2015, 8, 7278-7308.

44. Moros, M., Gonzalez-Moragas, L., Tino, A., Laromaine, A. ,Tortiglione, C., Invertebrate Models for Hyperthermia: What We Learned from Caenorhabditis Elegans and Hydra Vulgaris. In Nanomaterials for Magnetic and Optical Hyperthermia Applications, R. Fratila, J. M. d. 1. F., Ed. Elsevier,: 2018. 
45. Tortiglione, C.; Antognazza, M. R.; Tino, A.; Bossio, C.; Marchesano, V.; Bauduin, A.; Zangoli, M.; Morata, S. V.; Lanzani, G. Semiconducting Polymers are Light Nanotransducers in Eyeless Animals. Sci. Adv. 2017, 3, e1601699.

46. Moros, M.; Kyriazi, M. E.; El-Sagheer, A. H.; Brown, T.; Tortiglione, C.; Kanaras, A. G. DNA-Coated Gold Nanoparticles for the Detection of mRNA in Live Hydra Vulgaris Animals. ACS Appl. Mater. Interfaces 2018, 11, 13905-13911.

47. Xu, G.; Zeng, S.; Zhang, B.; Swihart, M. T.; Yong, K. T.; Prasad, P. N. New Generation Cadmium-Free Quantum Dots for Biophotonics and Nanomedicine. Chem. Rev. 2016, 116, 12234-12327.

48. Thomas, A., Nair P. V., Thomas, K. G. InP Quantum Dots: An Environmentally Friendly Material with Resonance Energy Transfer Requisites. J. Phys. Chem. C. 2014, 118, 3838-3845.

49. Tabei, Y.; Sonoda, A.; Nakajima, Y.; Biju, V.; Makita, Y.; Yoshida, Y.; Horie, M. Intracellular Accumulation of Indium Ions Released from Nanoparticles Induces Oxidative Stress, Proinflammatory Response and DNA Damage. J. Biochem. 2016, 159, 225-237.

50. National Toxicology, P., Toxicology and carcinogenesis studies of indium phosphide (CAS No. 22398-90-7) in F344/N rats and B6C3F1 mice (inhalation studies). National Toxicology Program technical report series 2001, (499), 7-340.

51. Yaghini, E.; Turner, H. D.; Le Marois, A. M.; Suhling, K.; Naasani, I.; MacRobert, A. J. In vivo Biodistribution Studies and ex Vivo Lymph Node Imaging Using Heavy Metal-Free Quantum Dots. Biomaterials 2016, 104, 182-191.

52. Yaghini, E.; Turner, H.; Pilling, A.; Naasani, I.; MacRobert, A. J. In Vivo Biodistribution and Toxicology Studies of Cadmium-Free Indium-Based Quantum Dot Nanoparticles in a Rat Model. Nanomedicine 2018, 14, 2644-2655.

53. Zhang, Y.; Hong, G.; Zhang, Y.; Chen, G.; Li, F.; Dai, H.; Wang, Q. Ag 2 S Quantum Dot: a Bright and Biocompatible Fluorescent Nanoprobe in the Second Near-Infrared Window. ACS Nano 2012, 6, 3695-3702.

54. Mattera, L.; Bhuckory, S.; Wegner, K. D.; Qiu, X.; Agnese, F.; Lincheneau, C.; Senden, T.; Djurado, D.; Charbonniere, L. J.; Hildebrandt, N.; Reiss, P. Compact Quantum Dot-Antibody Conjugates for FRET Immunoassays with Subnanomolar Detection Limits. Nanoscale 2016, 8, 11275-11283.

55. Lim J.; Bae W. K.; Lee D.; Nam M. K.; Jung J.; Lee C.; Char K.; Lee S. InP@ZnSeS, Core@Composition Gradient Shell Quantum Dots with Enhanced Stability. Chem. Mater. 2011, 23, 4459-4463.

56. Loomis, W. F., and Lenhoff, H. M. Growth and Sexual Differentiation of Hydra in Mass Culture. J. Exp. Zool. 1956, 132, 555-574.

57. Cotte, M.; Pouyet E.; Salomé, M.; Rivard, C.; De Nolf, W.; Castillo-Michel, H.; Fabris, T.; Monico, L.; Janssens, K.; Wang, T.; Sciau, P.; Verger, L.; Cormier, L.; Dargaud, O.; Brun, E.; Bugnazet, D.; Fayard, B.; Hesse, B.; Pradas del Real, A. E.; Veronesi, G.; Langlois, J.; Balcar, N.; Vandenberghe, Y.; Solé, V. A.; Kieffer, J.; Barrett, R.; Cohen, C.; Cornu, C.; Baker, R.; Gagliardini, E.; Papillon, E.; Susini, J. The ID21 X-Ray and Infrared Microscopy Beamline at the ESRF: Status and Recent Applications to Artistic Materials. J. Anal. At. Spectrom. 2017, 32, 477493.

58. Solé, V. A.; Papillon, E.; Cotte, M.; Walter, P.; Susini, J. A Multiplatform Code for the Analysis of Energy-Dispersive X-Ray Fluorescence Spectra. Spectrochim. Acta B. 2007, 62, 6368.

59. Ravel, B.; Newville, M. ATHENA, ARTEMIS, HEPHAESTUS: Data Analysis for XRay Absorption Spectroscopy Using IFEFFIT. J. Synchrotron Radiat. 2005, 12, 537-541. 
60. Figueiredo, M.-O.; Da Silva, T. P.; De Oliveira, D.; Rosa, D. Indium-Carrier Minerals in Polymetallic Sulphide Ore Deposits: A Crystal Chemical Insight into an Indium Binding State Supported by X-ray Absorption Spectroscopy Data. Minerals 2012, 2, 426-434.

\section{TOC Graphic}

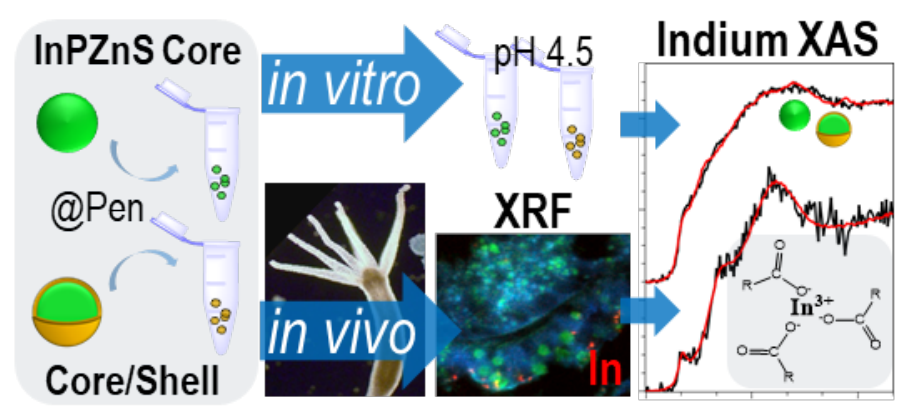

